\title{
Triple tubostomy and its outcome for blunt duodenal injury
}

\author{
Narendra Pandit, Tek Narayan Yadav, Laligen Awale, Shailesh Adhikary
}

Department of Surgery, B. P. Koirala Institute of Health Science, Dharan, Nepal

Correspondence: Dr. Narendra Pandit, Department of Surgery, B. P. Koirala Institute of Health Science, Dharan, Nepal

Email: narendrapandit111@gmail.com

\begin{abstract}
Introduction: Blunt duodenal injury in an uncommon form of abdominal injuries, which comprises less than $5 \%$ of all injuries. The diagnosis and management are challenging, because of delays in diagnosis due to subtle signs and symptoms in its early stage of presentation. Primary repair along with triple tubostomy (gastrostomy, retrograde duodenostomy and feeding jejunostomy) is a simple and safe method of damage control surgery in this group of patients. This study aims to report our experience in the management of this uncommon procedure.

Methods: This is a retrospective analysis of the patients undergoing triple tubostomy (TT) for blunt duodenal injury at the Department of Surgery, B.P.Koirala Institute of Health Sciences (BPKIHS), Dharan, over a three and half years. The study included demographics, clinical profile, length of hospital stay, postoperative morbidity (duodenal fistula), rate and timing of spontaneous closure of fistula and mortality.

Results: Eleven (6.7\%) patients out of 164 blunt trauma abdomen had sustained a duodenal injury. Eight patients who underwent TT were included in the study. The mean age of the patient was 31.8 years (range: 18-67), with a male: female ratio of $3: 1$. The mean time to trauma and presentation was 4.25 days. The most common site of injury was the second part of the duodenum (87.5\%), AAST grade III was seen in $62.5 \%$, two (25\%) patients were in shock at presentation. Eight patients required primary closure with triple tubostomy. Postoperatively, all patients had a duodenal fistula, which closed spontaneously in 6 (75\%) patients at a mean duration of 17 days, with a mean postoperative length of hospital stay of 33.5 days. The remaining two $(25 \%)$ patients died of an active fistula.

Conclusion: Blunt duodenal trauma, when presented late can be managed with primary closure and triple tubostomy with acceptable postoperative outcomes.
\end{abstract}

Keywords: Duodenal injury; Duodenostomy; Triple tube drainage.

\section{Introduction}

Duodenal trauma is an uncommon form of injury which comprises only 3 to $5 \%$ of all abdominal traumas. ${ }^{1,2}$ Most of the injuries are penetrating or a gunshot $(70 \%)$, while the remaining is caused by the blunt forces. ${ }^{3}$ The diagnosis and management of the duodenal injury, especially following blunt trauma is challenging, because of the retroperitoneal location of the most part of the duodenum, leading to subtle symptoms and lack of peritonism in its early stage. Moreover, they have a delayed presentation (> 24hrs), ${ }^{4}$ associated with other intraabdominal organs, and major bile duct and vessel injury, further complicating the management. All this leads to increased morbidity ( 25 to $66 \%$ ) and mortality (11 to $33 \%)^{4,5,6}$ 
Primary repair is the treatment of choice for patients with complex duodenal injury. To prevent the duodenal suture line dehiscence/fistula in high-risk injuries, there are various innovative and temporizing methods available such as pyloric exclusion, duodenal diverticulization and triple tubostomy (TT). ${ }^{1,3}$ However, there is no single method that completely eliminates the risk of duodenal fistula. Triple tubostomy (tube gastrostomy, retrograde tube duodenostomy, and feeding jejunostomy) is considered as a viable and simplest option in an emergency setting. ${ }^{7,8}$ In this study, we report our experience of this uncommon procedure, with the aim of assessing postoperative complications and its outcome.

\section{Methods}

A retrospective study of the patients undergoing TT for blunt duodenal injury at B.P.Koirala Institute of Health Sciences (BPKIHS), a tertiary care referral center in Eastern Nepal from June 2015, to February 2019 was performed. Patient information including demographics, mechanism of injury, duration of injury, shock at presentation, associated injury, site and grade of duodenal injury as per American Association for the Surgery of Trauma (AAST) was collected. ${ }^{9}$ The presence of duodenal injury was established and confirmed on the basis of persistent upper abdominal pain, raised total leucocyte counts, raised serum amylase/ lipase level and computed tomography (CT) imaging findings. The diagnostic criteria for duodenal injury on CT were retroperitoneal/paraduodenal air, duodenal contrast extravasation or duodenal wall thickening. Patients with duodenal injury requiring triple tubostomy were only included in the study. Patients with penetrating duodenal injury or those requiring only primary repair without TT were excluded.

Surgery was performed by primary closure of the duodenal perforation by a single layer interrupted sutures. TT, which included tube gastrostomy (16F), retrograde tube duodenostomy (14F) and antegrade feeding jejunostomy ((10F) were performed (Figure 1). Moreover, the periduodenal drain was placed to control the duodenal suture line leak. The daily tubostomy output, need for parenteral nutrition, and time to closure of duodenal suture line leak was noted. Postoperative outcomes that included complications, re-exploration, readmission, postoperative length of hospital stay and in hospital/90-days mortality were recorded.

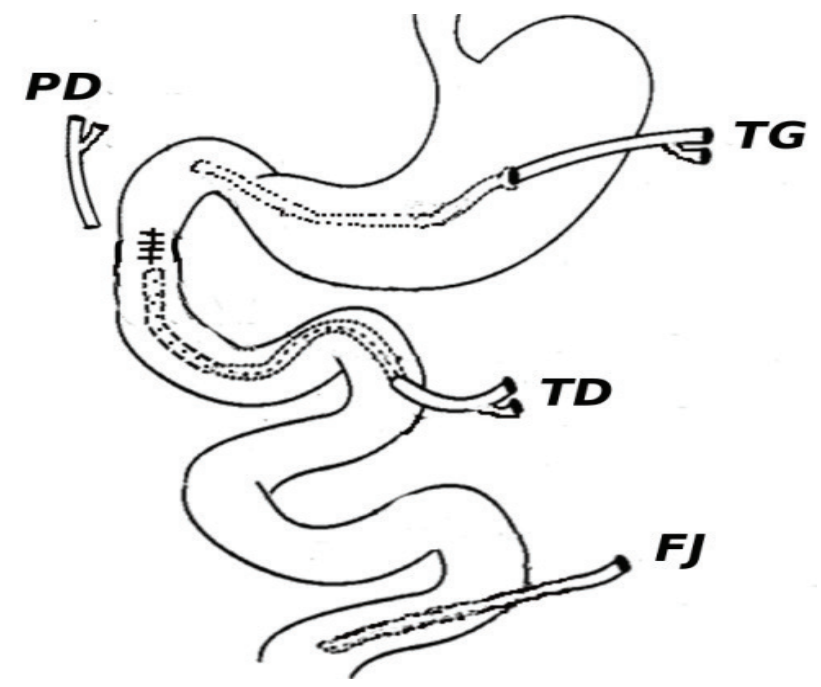

Figure 1. Diagramatic representation of triple tubostomy. TG-Tube Gastrostomy with its tip in the first part of Duodenum. TD- Retrograde Tube Duodenostomy with its tip in the second part of the duodenum. FJ- Antegrade Feeding Jejunostomy. PDPeriduodenal Drain.

\section{Results}

A total of 164 patients of abdominal trauma were managed during the study period. Among them, 11 (6.7\%) patients sustained a duodenal injury, and eight (4.9\%) patients required primary closure (PC) with TT. Eight patients were included in the study. The mean age of the patients was $31.8 \pm 14.14$ years (range $=18-67$ years) with a male: female ratio being $3: 1$. The mode of injury was motor vehicle injury in $5(62.5 \%)$ patients, blunt blow-out injury with bicycle handle-bar in $2(25 \%)$ and physical assault in $1(12.5 \%)$ patients. The mean time interval between trauma and presentation to the hospital was $4.25 \pm 1.7$ days (range= 2-7 days).

According to AAST grading of duodenal injury, 3 (37.5\%) patients had grade II and 5 (62.5\%) had grade III injury (Figure 2). Only one patient had an associated grade II liver injury. The most common anatomical site of duodenal laceration was D2 (87.5\%) followed by D3 and D1 (Table 1). One patient had a huge hematoma involving the $\mathrm{D} 2 /$ D3 portion with an underlying perforation (Figure 3). Two (25\%) patients were hemodynamically unstable during the presentation and had to be aggressively resuscitated. One patient referred from another center underwent unexpected re-exploration and TT following primary closure of duodenal injury. The patient had an uncontrolled duodenal fistula on a postoperative day 4 (Patient 4). 
Table 1: Demography and clinical profile of the patients with duodenal injury

\begin{tabular}{|c|c|c|c|c|c|c|c|c|}
\hline Case & 1 & 2 & 3 & 4 & 5 & 6 & 7 & 8 \\
\hline Age,years/gender & $28 / \mathrm{M}$ & $18 / \mathrm{M}$ & $67 / \mathrm{M}$ & $32 / \mathrm{F}$ & $32 / \mathrm{F}$ & $28 / \mathrm{M}$ & $30 / \mathrm{M}$ & $20 / \mathrm{M}$ \\
\hline Mechanism of injury & Blunt & Blunt & Blunt & Blunt & Blunt & Blunt & Blunt & Blunt \\
\hline Site of duodenum (D) & D2/D3 & $\mathrm{D} 2 / \mathrm{D} 3$ & D2 & $\mathrm{D} 1 / \mathrm{D} 2$ & D3 & D2 & $\mathrm{D} 2$ & $\mathrm{D} 2 / 3$ \\
\hline $\begin{array}{l}\text { AAST grade of } \\
\text { injury }\end{array}$ & III & II(Hematoma) & III & II & III & III & III & II \\
\hline Associated injury & $\begin{array}{l}\text { Liver injury } \\
\text { (grade II) }\end{array}$ & no & no & no & no & no & no & no \\
\hline $\begin{array}{l}\text { Duration of injury at } \\
\text { presentation (days) }\end{array}$ & 5 & 7 & 5 & 4 & 6 & 3 & 2 & 2 \\
\hline Shock at presentation & no & no & yes & no & yes & no & no & no \\
\hline
\end{tabular}

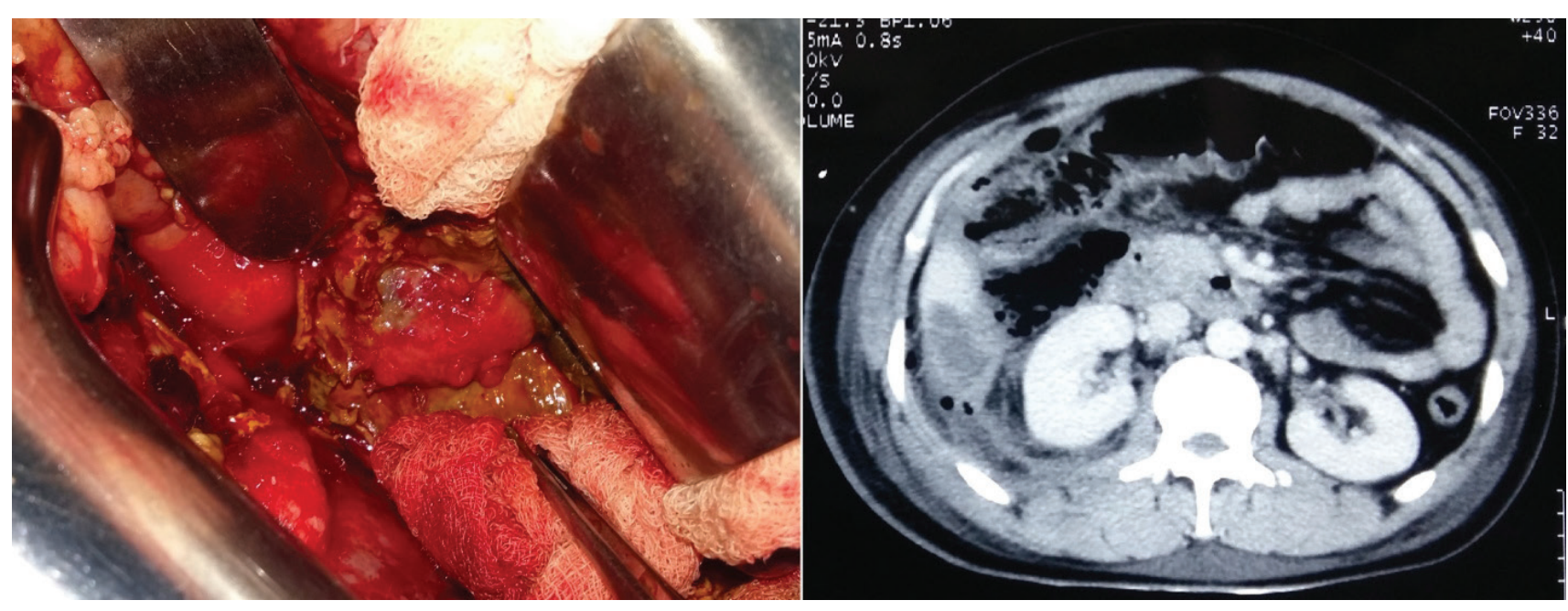

Figure 2: Contrast CT abdomen (right) showing extensive periduodenal and retroduodenal air, suggesting duodenal perforation. Note (left) the multiple perforations on the second and third parts of the duodenum covering threefourth of the circumference of the bowel.

Re-operation had to be performed in one case, who developed intrabdominal bleeding from the drain site. The mean daily output from the tube was $1438 \mathrm{ml}$ (range: $400-2500 \mathrm{ml}$ ). Additional parenteral nutrition was required in $4(50 \%)$ patients. The duodenal fistula was seen in all (100\%) patients, which was inevitable. Among them, six (75\%) patients had spontaneous closure in the meantime of 17 days (range: 7-38 days). The median length of postoperative hospital stay was 33.5 days (range $=3-55$ days). There were $2(25 \%)$ in-hospital mortality on the third and $35^{\text {th }}$ postoperative days possibly due to ongoing sepsis. Both had active duodenal fistulae (Table 2). 
Table 2: Surgery and postoperative outcome of the patients with duodenal injury

\begin{tabular}{|c|c|c|c|c|c|c|c|c|}
\hline Case & 1 & 2 & 3 & 4 & 5 & 6 & 7 & 8 \\
\hline $\begin{array}{l}\text { Re- } \\
\text { surgery }\end{array}$ & no & no & no & no & no & no & yes & no \\
\hline $\begin{array}{l}\text { Re- } \\
\text { admission }\end{array}$ & $\begin{array}{l}\text { yes (Dehydration, } \\
\text { high-output tube } \\
\text { gastrostomy/ } \\
\text { duodenostomy) }\end{array}$ & no & no & no & no & no & no & no \\
\hline \multirow[t]{3}{*}{ Morbidity } & $\begin{array}{l}\text { 1.Duodenal suture } \\
\text { line leak from } \\
\text { wound/drain }\end{array}$ & $\begin{array}{l}\text { 1.Duodenal } \\
\text { suture line } \\
\text { leak from } \\
\text { the drain }\end{array}$ & $\begin{array}{l}\text { Duodenal } \\
\text { suture line } \\
\text { leak }\end{array}$ & $\begin{array}{l}\text { 1.Duodenal } \\
\text { suture line } \\
\text { leak }\end{array}$ & $\begin{array}{l}\text { 1.Duodenal } \\
\text { suture line } \\
\text { leak }\end{array}$ & $\begin{array}{l}\text { 1.Duodenal } \\
\text { suture line } \\
\text { leak } \\
\text { Pulmonary } \\
\text { embolism }\end{array}$ & $\begin{array}{l}\text { 1.Bleeding } \\
\text { from drain site } \\
\text { (intraabdominal) }\end{array}$ & $\begin{array}{l}\text { 1.Duodenal } \\
\text { suture line } \\
\text { leak }\end{array}$ \\
\hline & $\begin{array}{l}\text { 2.Catheter-related } \\
\text { bloodstream } \\
\text { infection }\end{array}$ & & & $\begin{array}{l}\text { 2.Wound } \\
\text { dehiscence }\end{array}$ & $\begin{array}{l}\text { 2.Bleeding } \\
\text { due to } \\
\text { coagulopathy }\end{array}$ & 2.Dehydration & $\begin{array}{l}\text { 2.Duodenal } \\
\text { suture line leak }\end{array}$ & \\
\hline & $\begin{array}{l}\text { 3.Intrabdominal } \\
\text { collection }\end{array}$ & & & $\begin{array}{l}\text { 3.Fungal } \\
\text { sepsis }\end{array}$ & $\begin{array}{l}\text { 3.Wound } \\
\text { dehiscence }\end{array}$ & $\begin{array}{l}\text { 3.Progressive } \\
\text { sepsis }\end{array}$ & & \\
\hline $\begin{array}{l}\text { Hospital } \\
\text { stay, days }\end{array}$ & 55 & 32 & 3 & 38 & 45 & 35 & 23 & 18 \\
\hline Mortality & no & no & yes & no & no & yes & no & no \\
\hline
\end{tabular}
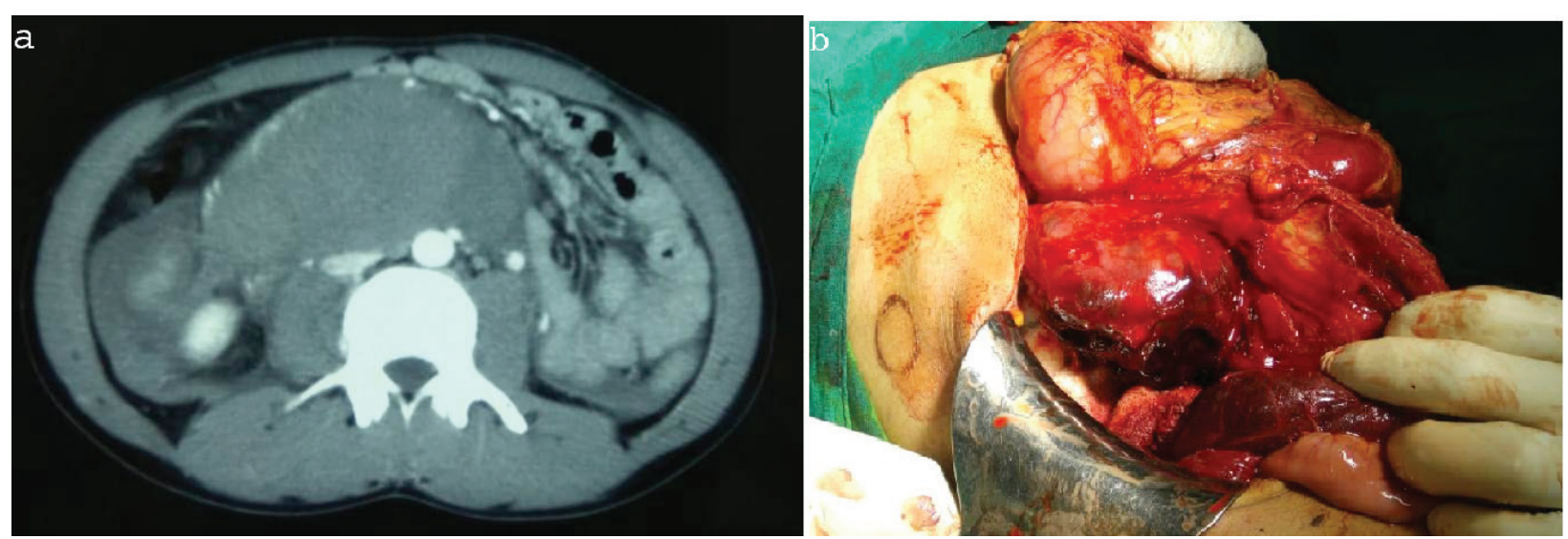

Figure 3: Contrast CT abdomen (a) showing a large $(12 \times 10 \mathrm{~cm})$ intramural duodenal hematoma, compressing the duodenal lumen at the periphery. Intraoperative photograph (b) undergoing evacuation of the clot. 


\section{Discussion}

Blunt duodenal injury is a blow out injury, where the diagnosis and management remain challenging, because of its delayed presentation. The most common site of injury is the second or third part of the duodenum. ${ }^{6}$ When feasible and presented early, primary repair (closure or resection anastomosis) is the preferred treatment of choice. ${ }^{1,3}$ Most of the largest series of duodenal injury comes from the Talving et $\mathrm{al},{ }^{10}$ from South Africa, where the results are quite favorable with primary repair, however, the mode of injury in the study was predominantly penetrating $(80 \%)$, and the presentation, diagnosis, and operative intervention was early.

Blunt duodenal injury when presented late, is a highrisk injury. Primary repair along with some adjunct procedures to prevent duodenal suture line leak has to be performed. ${ }^{2,11}$ Triple tubostomy, as was done in our series, was safe with only $2(25 \%)$ mortalities, and almost $100 \%$ morbidities, with duodenal suture line leak occurring in all of our patients. Moreover, it also increases the length of hospital stay, which too corresponds to the increased cost of treatment. In the present study, the median length of stay was 33 days (vs. 7 days in primary closure). It was Stone and Fabian et al, who first described the procedure of triple tubostomy in 1979 with only one leak rate out of a total of 237 patients. It diverts bile, gastric and pancreatic secretions ( 3 liters/day), lowers intraluminal pressure and favors healing of suture line. ${ }^{12,13}$

Since then, surprisingly, the same results as that of Stone et al have not been duplicated by other studies, and on the contrary, other studies claimed an increased rate of leak rate from the duodenal suture line by intraluminal use of tubes. ${ }^{14}$ The high leak rate in our study was expected, as the presentation was delayed, the injury was high grade, the retroperitoneum was severely inflamed/infected with an edematous/ thickened duodenum leading to a precarious closure. Moreover, we had no other options left, besides the simplest duodenal content diversion, wide periduodenal drainage which could subsequently form a controlled external fistula with additional postoperative nutritional support.

The duodenal fistulas in various studies vary up to $66 \%$ depending on the timing of presentation, associated injury, and shock at presentation. ${ }^{15,16}$ In our study, the fistula was higher $(100 \%)$ than the other studies. The spontaneous fistula closure happened in $6(75 \%)$ out of 8 cases with a mean time of 17 days. The remaining 2 cases died of active fistulae. In a study by Weale et al, ${ }^{16}$ from a major trauma center in South Africa reported, morbidity (leak) and mortality also depend on the duodenal AAST grade, apart from the timing of presentation. The morbidity ( $66 \%$ vs. $1.6 \%)$ and mortality (33\% vs. $10 \%)$ were significantly higher for grade 3 injury, with respect to the lower grade $2 .{ }^{16}$

Since the 1990s, there are only anecdotal reports of management of blunt duodenal injury, presenting in a delayed fashion, and managed with triple tubostomy. Few studies could be noted, especially in difficult or giant duodenal ulcer perforation treated with TT, but with a high associated postoperative morbidities (duodenal fistulas and wound dehiscence). ${ }^{17,18}$

Other adjunct procedures that have been described following a duodenal repair are pyloric exclusion (PE) and duodenal diverticulization. However, PE has its own disadvantages. It increases the operating time, risk of adding an extra gastrojejunal anastomosis, its long term complications (marginal ulcer, anastomotic malignancy), increased cost of stapler, unpredictability of rate and time of spontaneous opening of pylorus closure and a trend towards higher overall complication rates compared to a simple repair (71\% vs. $33 \%){ }^{1,15}$ Moreover, the resident doctors or attending consultant may not be well versed with the appropriate performance of the uncommon procedure in an emergency setting. ${ }^{15} \mathrm{TT}$, based on the damage control principles, has that simplicity, with no increase in operating time and maintenance of normal gastrointestinal anatomy.

Similarly, duodenal diverticulization is an even more complex, time-consuming procedure and resects normal tissue in healthy patients in the setting of duodenal trauma. ${ }^{6}$ Moreover, in recent days it is hardly practiced and lacks English literature in the last 2 decades on its utility in duodenal trauma. Furthermore, in the last decade, the literature has demonstrated a shift away from more complex procedures in favor of simpler surgical techniques for the repair of duodenal injuries. ${ }^{6,11,19}$

The study is limited by the retrospective design, small sample size, and a lack of comparison (duodenal repair vis-a-vis triple tubostomy) group. However, it does give an insight into its simplicity, safety and an acceptable outcome in the management of an uncommon condition.

\section{Conclusion}

Blunt duodenal trauma, when presented late with retroperitoneal infections and inflammation can be managed with primary repair and triple tubostomy with acceptable postoperative morbidity and mortality.

Conflict of interest: None

Funding: None 


\section{References}

1. Coleman JJ, Zarzaur BL. Surgical Management of Abdominal Trauma. Surg Clin North Am. 2017 Oct;97(5):1107-17.

2. García Santos E, Soto Sánchez A, Verde JM, Marini CP, Asensio JA, Petrone P. Duodenal Injuries Due to Trauma: Review of the Literature. Cirugía Española (English Ed. 2015 Feb;93(2):68-74.

3. Pandey S, Niranjan A, Mishra S, Agrawal T, Singhal B, Prakash A et al. Retrospective analysis of duodenal injuries: A comprehensive overview. Saudi J Gastroenterol. 2011;17(2):142.

4. Velmahos GC, Constantinou C, Kasotakis G. Safety of Repair for Severe Duodenal Injuries. World J Surg. 2008 Jan 22;32(1):7-12.

5. Ivatury RR, Malhotra AK, Aboutanos MB, Duane TM. Duodenal Injuries: A Review. Eur J Trauma Emerg Surg. 2007 Jun 6;33(3):231-7.

6. Degiannis E, Boffard K. Duodenal injuries. Br J Surg. 2000 Nov 1;87(11):1473-9.

7. Bhattacharjee HK, Misra MC, Kumar S, Bansal VK. Duodenal perforation following blunt abdominal trauma. J Emerg Trauma Shock 2011;4:514-7.

8. Isik B, Yilmaz S, Kirimlioglu V, Sogutlu G, Yilmaz M, Katz D. A Life-saving but Inadequately Discussed Procedure: Tube Duodenostomy. Known and Unknown Aspects. World J Surg. 2007 Jul 13;31(8):1616-24.

9. Rathore MA, Andrabi SIH, Najfi SM, Chaudhry Z, Chaudhry AM. Injuries to the duodenum - prognosis correlates with body Injury Severity Score: A prospective study. Int J Surg. 2007 Dec;5(6):388-93.

10. Talving P, Nicol AJ, Navsaria PH. Civilian duodenal gunshot wounds: Surgical management made simpler. World J Surg . 2006 Apr;30(4):488-94.

11. Bekker W, Kong V, Laing G, Bruce J, Manchev V, Clarke D. The spectrum and outcome of blunt trauma related enteric hollow visceral injury. Ann R Coll Surg Engl. 2018 Apr;100(4):290-4.

12. Stone HH, Fabian TC. Management of Duodenal Wounds. J Trauma Inj Infect Crit Care. 1979 May;19(5):334-9.
13. Schroeppel TJ, Saleem K, Sharpe JP, Magnotti LJ, Weinberg JA, Fischer PE et al. Penetrating duodenal trauma. J Trauma Acute Care Surg. 2016 Mar;80(3):461-5.

14. Ivatury RR, Nassoura ZE, Simon RJ, Rodriguez A. Complex duodenal injuries. Surg Clin North Am. 1996 Aug;76(4):797-812.

15. Ordoñez C, García A, Parra MW, Scavo D, Pino LF, Millán M et al. Complex penetrating duodenal injuries. J Trauma Acute Care Surg. 2014 May;76(5):1177-83.

16. Weale RD, Kong VY, Bekker W, Bruce JL, Oosthuizen GV, Laing GL et al.Primary repair of duodenal injuries: A retrospective cohort study from a major trauma centre in South Africa. Scand J Surg. 2019 Jan 29:1457496918822620. [Epub ahead of print]

17. Agarwal N, Malviya NK, Gupta N, Singh I, Gupta S. Triple tube drainage for "difficult" gastroduodenal perforations: A prospective study. World J Gastrointest Surg. 2017 Jan 27;9(1):19-24.

18. Ateeq M, Akram M, Gondal SH, Jehan S, Bhopal FG. Tube duodenostomy - A safe approach for the management of "complex duodenal injuries" in poly trauma patients. Pakistan J Med Heal Sci. 2012;6(1):242-45.

19. Aiolfi A, Matsushima K, Chang G, Bardes J, Strumwasser A, Lam L et al. Surgical Trends in the Management of Duodenal Injury. J Gastrointest Surg. 2019 Feb;23(2):264-269. 